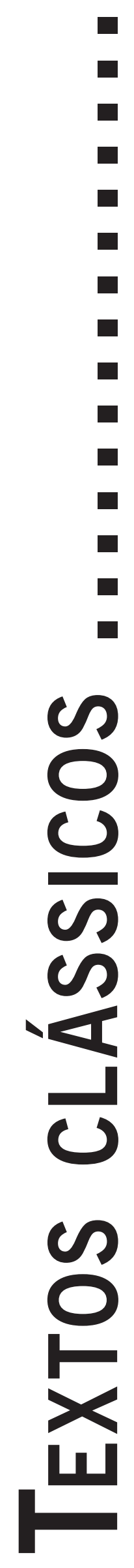




\title{
TEXTOS CLÁSSICOS
}

\section{CARL ROGERS DIALOGUES ${ }^{1}$}

\author{
Diálogo entre Carl Rogers e Martin Buber ${ }^{2}$
}

(1957)

\section{Introdução: Martin Buber ${ }^{3}$}

Martin Buber nasceu em Viena, em 1878. Desde os três anos de idade, quando seus pais se divorciaram, morou com seu avô, um rico homem de negócios, erudito respeitado e líder na comunidade judaica. Buber foi formado na tradição da racionalidade, crítica lógica e pesquisa histórica da Europa Ocidental. Em contraste, durante os verões na Europa Oriental, foi profundamente tocado pela tradição Hassídica judaica, que enfatiza a relação direta, mística, espontânea e jubilosa do homem com Deus.

Depois de estudar filosofia e história da arte nas Universidades de Viena (PhD, 1904), Berlin, Leipzig e Zurich, lecionou filosofia e religião em vários institutos e universidades. Entre 1923 e 1933, foi professor de teologia Judaica (a única cadeira do gênero em uma universidade alemã), história da religião e ética na Universidade de Frankfurt. Quando os alunos judeus foram excluídos das universidades alemãs em 1933, tornou-se diretor do Departamento Central para a Educação de Adultos Judeus. Casou-se com Paula Winkler, que depois veio a se tornar uma romancista respeitada.

No começo do século, Buber se tornou o principal intérprete do Hassidismo e do misticismo judaico (e.g., Os Contos do Rabino Nachman, 1906, traduzido ${ }^{4}$ em 1956; A Lenda do Baal-Shem, 1908, traduzido em 1955), explicando a vitalidade da tradição mística judaica e escrevendo suas próprias versões de centenas de contos e parábolas

\footnotetext{
Nossos mais sinceros agradecimentos aos editores Howard Kirschenbaum e Valerie Land Henderson, bem como a Natalie Rogers, pela gentileza de autorizar a tradução do presente diálogo (Nota do Editor)

2 Originalmente publicado em Carl Rogers: Dialogues, Edited by Howard Kirschenbaum \& Valerie Land Henderson, Houghton Mifflin Company, Boston, 1989 (pp. 41-63). Algumas partes do diálogo, que permaneciam obscuras ou necessitavam de complemento, foram completadas a partir de consultas a duas outras versões do mesmo texto, a saber: o Apêndice ao livro de Martin Buber, The Knowledge of Man (London: Allen \& Unwin), publicado em 1965; e o livro The Martin Buber-Carl Rogers Dialogue. A New Transcript with Commentary, editado por Rob Anserson \& Kenneth Cissna, e publicado em 1997 pela State University of New York Press (Nota do Editor).

3 Introdução dos editores na publicação original (Nota de Tradução).

4 Aqui se trata das traduções para o inglês (Nota de Tradução).
}

hassídicas. Movendo-se gradualmente para além do misticismo, mas certamente influenciado pelo Hassidismo, Buber desenvolveu uma filosofia centrada no "encontro" entre a pessoa, o "Eu", e Deus, o "Tu". Deus como "Tu", não tem fronteiras e inclui tudo. Um verdadeiro encontro entre pessoas ou entre uma pessoa e a arte também pode ser uma relação Eu-Tu, pois a outra pessoa ou a arte é experienciada sem rótulos ou limites e é, consequentemente, conectada a tudo, a Deus. Relações "Eu-Isso", por outro lado, são mais típicas do viver cotidiano, com a outra pessoa ou meio/agente/veículo transmissor percebido como objeto, como separado.

A principal tese de Buber era que "a vida é encontro". Ele descreveu um incidente trágico no qual um jovem perturbado veio procurar seu conselho. Buber estava preocupado e falou com ele, mas não o "encontrou" realmente. O jovem foi embora e cometeu suicídio. A salvação, para Buber, não poderia ser encontrada na glorificação do indivíduo ou do coletivo, mas na relação. Ele via a única esperança para o futuro no "diálogo aberto", não num "desmascarar" do "adversário".

Sua desconcertante produção literária incluiu mais de sessenta volumes em teologia, história judaica, filosofia, religião comparada, arte e educação, incluindo Daniel (1913), Ich und Du (1923; I and Thou, 1937), The Kingship of God (1932), For the Sake of Heaven (um romance, 1945), e The Prophetic Faith (1950). Em 1925, juntamente com Franz Rosenzweig, iniciou uma nova tradução da Bíblia para o alemão, que foi concluída em 1962.

A partir de 1899, Buber era também um sionista de destaque, atuando como editor cultural para o jornal sionista Die Welt, e como fundador e editor, por dez anos, do Der Jude, um dos principais periódicos para comunidade judaica de língua alemã, no qual ele procurou clarificar o destino espiritual do povo judeu na Europa e na Palestina. Em 1926, Der Jude foi ampliado para Die Kreatur, que era coeditado por um católico alemão e um protestante.

Forçado a fugir da Alemanha em 1938, emigrou para Israel, onde se tornou professor de Filosofia Social na Universidade Hebraica de Jerusalém. Além de seus escritos e docência em religião e filosofia social, Buber dirigiu o Instituto para Educação de Adultos (de 1949 a 1953), 
que lidava com a assimilação cultural da vasta onda de imigrantes judeus nos quatro anos subsequentes à independência de Israel. Seu sionismo, assim como ele propunha há meio século, incluía a forte defesa dos direitos civis e religiosos dos palestinos.

Depois da sua aposentadoria, em 1951, Buber viajou muito, incluindo várias viagens aos Estados Unidos, onde proferiu palestras em muitas das principais escolas teológicas e universidades. Apesar de Israel ter demorado em apreciá-lo, nos anos cinquenta, seu trabalho atingiu reconhecimento internacional. Na Alemanha, recebeu muitos prêmios importantes e homenagens. Reinhold Niebuhr se referiu a ele como "o maior filósofo judeu vivo". Outros comentaristas apontaram que ele "influenciou profundamente o pensamento contemporâneo, incluindo a teologia Cristã", e que "a sua relevância para o trabalho de quase todos os autores importantes do século... é indiscutível". Commonweal ${ }^{5}$ escreveu que Buber tinha "uma imensa influência em pensadores de todas as crenças, incluindo... Paul Tillich". Hermann Hesse disse que Buber era "uma das principais e mais valiosas personalidades da literatura mundial contemporânea". Yale Review disse que seu pensamento "entrou como um ingrediente vital na nova teologia Cristã, e também em boa parte das mais significativas filosofias sociais do nosso tempo".

Descrito como "um pequeno homem com uma cabeça enorme e uma barba branca flutuante, que lembra um profeta de tempos antigos", Buber foi eventualmente reconhecido como um vidente e um sábio, por seus compatriotas. Os israelenses prantearam seu falecimento em 13 de junho de 1965, aos oitenta e sete anos. Em homenagem ao homem que lutou consistentemente por seus direitos, os estudantes árabes da Universidade Hebraica depositaram uma coroa em seu esquife quando das celebrações fúnebres.

O diálogo de Martin Buber com Carl Rogers aconteceu em Ann Arbor, Michigan, em 18 de abril de 1957, em uma conferência sobre o trabalho de Buber, organizada pela Universidade de Michigan. O diálogo é moderado por Maurice Friedman, um proeminente filósofo americano.

\section{Diálogo entre Carl Rogers e Martin Buber ${ }^{6}$}

REV. DEWITT BALDWIN: Esta será uma oportunidade fora do comum - uma sessão onde poderemos desfrutar de uma hora quando você pode pensar juntamente com dois homens que querem compreender melhor suas próprias idéias. Eu só quero apresentar uma pessoa e deixá-lo falar pelos outros. O seu moderador é o professor Maurice S. Friedman, professor de filosofia no Sarah Lawrence

\footnotetext{
5 Periódico sobre religião, política e cultura editado por Católicos leigos (Nota da Tradução).

6 Foram retiradas todas as expressões e onomatopéias que, apesar de constarem no diálogo transcrito, não correspondem ao texto corrido. Desta feita, procuramos manter o diálogo na forma mais concreta e fluida possível (Nota do Editor).
}

College, em Bronxville, New York. Professor Friedman é um dos melhores intérpretes americanos de Martin Buber. Ele fez sua graduação em Harvard, sua pós-graduação na Ohio State e na Universidade de Chicago, onde completou seu doutorado. Ele é mais conhecido em relação a Martin Buber por seu livro Martin Buber, the Life of Dialogue ${ }^{7}$. E, então, Maurice, eu passo a você a palavra, e sei que você irá se divertir.

MAURICE FRIEDMAN: Obrigado, DeWitt Baldwin. Eu tenho muito prazer em fazer esta moderação porque eu poderia dizer que talvez tenha iniciado o diálogo entre o Professor Buber e o Professor Rogers alguns anos atrás, quando alguém apontou para mim as semelhanças entre o pensamento dos dois. Eu escrevi ao professor Rogers, que gentilmente me forneceu alguns de seus trabalhos, e nos correspondemos por algum tempo. Então, eu mandei esse material ao professor Buber, incluindo alguns artigos do Dr. Rogers, e consequentemente, eu fiquei realmente muito feliz quando surgiu a idéia dos dois falarem em diálogo aqui. Acredito que este é um encontro da maior significância, não somente em termos de psicoterapia, mas pelo fato de que esses dois homens ganharam a nossa admiração como pessoas, com uma abordagem para as relações pessoais e para um "tornar-se" pessoa. Existem tantas similaridades notáveis entre o pensamento dos dois que é tremendamente fascinante ter o privilégio de ouvi-los falar, um com o outro, e ver quais questões podem surgir. Meu papel como moderador é apenas, se a ocasião surgir, estimular estas questões ou interpretar de uma ou de outra forma. Não creio que vocês precisem que qualquer apresentação do Professor Buber, posto que a conferência está centrada nele. E estou certo de que vocês não precisam de uma apresentação do Dr. Rogers, também. Ele, é claro, é famoso há muitos anos como fundador do que ficou conhecido como terapia não-diretiva, hoje em dia rebatizada terapia centrada no cliente; e é diretor do Centro de Aconselhamento da Universidade de Chicago, onde tem estabelecido relações muito frutíferas com o corpo docente da teologia e dos cursos de personalidade e religião de lá. A forma deste diálogo será que Dr. Rogers levantará questões para o Dr. Buber, e Dr. Buber responderá, talvez com uma pergunta, talvez com uma afirmação. Eu os deixarei tomar a frente a partir daqui, Dr. Rogers.

CARL ROGERS: Uma coisa que eu gostaria de dizer à audiência antes de começar a falar com o Dr. Buber é que este é, muito certamente, um diálogo não ensaiado. As condições climáticas fizeram com que eu levasse o dia inteiro para chegar aqui e, então, foi somente há uma ou duas horas atrás que me encontrei com Dr. Buber, apesar de já tê-lo encontrado, muito tempo antes, em seus escritos.

Penso que a primeira pergunta que eu gostaria de fazer, Dr. Buber, pode soar um pouco impertinente, mas eu gostaria de explicá-la e, então, talvez, não parecerá impertinente. Tenho me perguntado como você tem vivido

\footnotetext{
Ainda inédito no Brasil (Nota do Editor)
} 
tão profundamente nas relações interpessoais e ganhado tal compreensão do indivíduo humano sem ser um psicoterapeuta? [Buber ri]. A razão pela qual eu pergunto é que me parece que muitos de nós vimos a sentir e experienciar alguns dos mesmos tipos de aprendizagens que você expressou em seus escritos, mas, muito frequentemente, nós chegamos a essas aprendizagens através de nossa experiência em psicoterapia. Penso que há algo sobre a relação terapêutica que nos dá a permissão, quase a permissão formal, de entrar em um profundo e próximo relacionamento com uma pessoa e, então, tendemos a aprender muito profundamente dessa forma. Penso em um psiquiatra amigo meu que diz que ele nunca se sente tão inteiro ou tão pessoa, quanto em suas entrevistas terapêuticas. E eu compartilho desse sentimento. E assim, se não for muito pessoal, eu estaria interessado em ouvir quais foram os canais de conhecimento que possibilitaram que você aprendesse tão profundamente sobre pessoas e relacionamentos?

MARTIN BUBER: Hmmmm. Esta é uma questão bastante biográfica. Acho que devo dar, ao invés de uma, duas respostas. Uma é que eu não sou um completo estranho em, digamos, psiquiatria, porque quando eu era um estudante, muito tempo atrás, eu estudei três períodos de psiquiatria e o que eles chamam na Alemanha PsychiatrischeKlinique. Eu estava muito interessado nesse último.

Veja, eu não estudei psiquiatria para me tornar um psicoterapeuta. Eu estudei três períodos, primeiro com Flechsig ${ }^{8}$ em Leipzig, onde estavam os alunos de Wundt ${ }^{9}$. Mais tarde, em Berlim, com Mendel, e um terceiro período com Bleuler, que foi o mais interessante dos três. Na época, eu era muito jovem, inexperiente e um rapaz não muito compreensivo. Mas tinha a sensação que queria saber sobre o homem, e o homem no chamado estado patológico. Mesmo então, eu duvidava que esse fosse o termo correto. Queria ver e, se possível, encontrar essas pessoas e, desde que posso me lembrar, estabelecer relações, uma relação real entre o que chamamos o homem são e o que chamamos o homem patológico. E isso eu aprendi, em alguma medida, na proporção em que um garoto de seus vinte anos pode aprender coisas como essas [Risadas].

Sobre o que, principalmente, constituiu o que você pergunta, foi algo diferente. Foi só uma certa inclinação para encontrar pessoas. E, tanto quanto possível, simplesmente modificar algo no outro, mas também, permitir que eu seja modificado por ele. Em qualquer evento, eu

\footnotetext{
8 Na versão original, há apenas um traço no lugar do nome de Flechsig, indicando que a palavra estava ininteligível. Em outras transcrições, contudo, há referência ao nome de Flechsig, indicado em outra transcrição por Friedman (consoante Rob Anderson \& Kenneth Cissna, em The Martin Buber-Carl Rogers Dialogue. A New Transcript with Commentary, New York: State University of New York Press, 1997) (Nota da Tradução).

9 Não fica perfeitamente claro se Buber se refere apenas aos alunos de Wundt ou a Wundt em si mesmo. Em outras transcrições há indicativos que Buber participou de exercícios de laboratório com o próprio Wundt (Ver G. Schaeder, The Hebrew Humanism of Martin Buber, Detroit: Wayne State University Press, 1973) (Nota da Tradução).
}

não tinha resistência... não colocava nenhuma resistência. Comecei como um jovem. Sentia que eu não tinha o direito de querer modificar o outro, se eu não estivesse aberto a ser modificado por ele, tanto quanto fosse legítimo. Algo deve ser mudado, e o seu toque, seu conceito é capaz de mudá-lo mais ou menos. Eu não posso estar, por assim dizer, acima dele e dizer, "Não! Eu estou fora do jogo. Você é louco”. E assim, a partir do meu - deixeme ver - houve duas fases em relação a isso. A primeira fase foi até o ano de 1819 [1918 ${ }^{10}$, ou seja, até quando eu tinha perto de quarenta anos. E então, em 1819, senti algo bastante estranho. Senti que tinha sido fortemente influenciado por algo que havia acabado naquele momento, ou seja, a Primeira Guerra Mundial.

ROGERS: Em 1918?

BUBER: M-hmmmm. Ela acabou naquele momento e, no decorrer da guerra, eu não havia sentido muito da sua influência. Mas, ao fim eu senti: "Oh, fui terrivelmente influenciado”, porque não podia resistir ao que estava acontecendo, e eu estava compelido a, poderia dizer, vivê-lo. Você entende? Coisas que estavam acontecendo naquele exato momento. Você pode chamar isso de imaginar o real. Imaginar o que estava acontecendo. Este imaginar, por quatro anos, me influenciou terrivelmente. Justamente quando acabou, acabou através de um certo episódio, em maio de 1919, quando um amigo meu, um grande amigo, um grande homem, foi morto pelos soldados antirrevolucionários, de uma forma muito bárbara, e eu agora, mais uma vez - e essa foi a última vez - fui compelido a imaginar esse assassinato, mas, não somente de forma óptica, mas, eu poderia dizer, justamente com o meu corpo. E este foi o momento decisivo, depois do qual, depois de alguns dias e noites nesse estado, eu senti: "Oh, algo foi feito a mim”. E, a partir de então, esses encontros com as pessoas, particularmente com as pessoas jovens, foram, tornaram-se, um tanto diferentes na forma. Eu tive uma experiência decisiva, experiência de quatro anos, muitas experiências concretas e, a partir daquele momento, eu tinha que dar algo além da minha simples inclinação para trocar pensamentos e sentimentos, e por aí afora. Eu tinha que dar o fruto de uma experiência.

ROGERS: M-hmmmm. Parece que você está dizendo que o conhecimento, talvez, ou parte dele, veio quando você tinha seus vinte anos, mas, então, parte da sabedoria que você tem sobre as relações interpessoais veio de querer encontrar pessoas abertamente, sem querer dominar. E então - eu vejo esta resposta se desdobrando em três e, então, em terceiro lugar, vem de realmente vivenciar a guerra mundial, mas vivenciando-a em seus próprios sentimentos e imaginação.

BUBER: Exatamente. Porque este último foi realmente, eu não posso expressá-lo em nenhuma outra linguagem,

\footnotetext{
${ }^{10}$ Nesse ponto Buber se confunde com as datas. Entre colchetes o ano correspondente à sua colocação de que tinha "quarenta anos". Em seguida, Rogers o corrige (Nota da Tradução).
} 
foi realmente um vivenciar com aquelas pessoas. Pessoas feridas, mortas na guerra.

ROGERS: Você sentiu seus ferimentos.

BUBER: Sim. Mas sentimento não é uma palavra suficientemente forte - a palavra "sentimento".

ROGERS: Vou fazer uma sugestão, mesmo que nos interrompa um pouco. Eu não consigo ficar de frente para o microfone e ficar de frente para você ao mesmo tempo. Você se incomodaria se eu virasse a mesa só um pouco? (Move a mesa).

BUBER: Assim está bem?

ROGERS: Parece melhor para mim.

FRIEDMAN: Enquanto ele está mudando, eu quero admitir que a questão do Professor Rogers me lembrou de um aluno de teologia de um seminário Batista que falou comigo a respeito do pensamento do Professor Buber e, quando ele estava saindo, disse; "eu tenho que fazer uma pergunta. Professor Buber é tão bom. Como é que ele não é cristão?" [Risos].

BUBER: Agora, eu posso contar-lhe uma história, não sobre mim, mas uma história que é verdadeira, não somente uma anedota. Um oficial cristão teve que explicar a algumas pessoas na guerra, na Segunda Guerra, explicar a eles - soldados - sobre os judeus. Ele começou, é claro, com a explicação do que Hitler significava, e assim por diante, e ele explicou a eles que os judeus não são simplesmente uma raça bárbara, que eles tinham uma grande cultura e, assim por diante, e então ele se dirigiu a um soldado judeu que estava ali, que sabia um pouco, e lhe disse: "agora, você vá em frente e conte a eles algumas coisas”. E esse jovem judeu contou-lhes sobre Israel e mesmo sobre Jesus. E, a isso, um dos soldados respondeu, "Você quer nos dizer que perante o seu Jesus, nós não temos sido um povo cristão?" [Risos].

ROGERS: Bem, eu gostaria de passar a uma questão sobre a qual tenho pensado frequentemente. Eu tenho me perguntado se seu conceito, que você denominou relação Eu-Tu, é similar com o que eu vejo como momentos efetivos na relação terapêutica? E, eu gostaria, se você me permitir, tomar um momento ou dois, para colocar o que eu vejo de essencial nisso e, então, você poderia tecer alguns comentários a partir do seu ponto de vista.

Eu sinto que quando estou sendo efetivo como terapeuta, eu entro na relação como uma pessoa subjetiva, não como um escrutinador, não como um cientista. Eu sinto também, que quando sou mais efetivo, então de alguma forma, estou relativamente inteiro naquela relação, ou a palavra que tem sentido para mim é transparente. Certamente, existem muitos aspectos da minha vida que não são trazidos para a relação, mas o que é trazido para a relação é transparente. Não há nada escondido. E eu penso, também, que em uma relação como essa, sinto uma disposição real para que essa outra pessoa seja o que ela é. Chamo a isso de aceitação. Não sei se essa é uma boa palavra para isso, mas meu sentido aqui é que estou disponível para que ele possua os sentimentos que ele pos- sui, que tenha as atitudes que tem, que seja a pessoa que é. E, então, outro aspecto que é importante para mim é que penso que nesses momentos sou capaz de perceber com bastante clareza como sua experiência lhe parece, realmente visualizando-a a partir de dentro dele e, ainda assim, sem perder contato com minha própria pessoalidade ou separação no processo. Então, se além daquelas coisas da minha parte, meu cliente ou a pessoa com quem estou trabalhando é capaz de perceber um pouco daquelas atitudes em mim, então, me parece que existe um real e experiencial encontro de pessoas, no qual cada um de nós é modificado. Penso que, às vezes, o cliente é modificado mais do que eu, mas penso que somos ambos modificados numa experiência desse tipo. Agora, vejo isso como tendo alguma semelhança com o tipo de coisa sobre o que você falou na relação Eu-Tu. Contudo, suspeito que há diferenças. Eu estaria muito interessado em seus comentários sobre como essa descrição lhe parece em relação ao que pensou em termos de duas pessoas se encontrando em uma relação Eu-Tu.

BUBER: Agora, eu poderia tentar fazer algumas perguntas, também, sobre o que você quis dizer. Primeiramente, eu gostaria de dizer, essa é a ação de um terapeuta. Esse é um exemplo muito bom de certo momento de existência dialógica. Quero dizer, duas pessoas têm certa situação em comum. Essa situação é, do seu ponto de vista - ponto não é uma boa palavra, mas vamos ver isso do seu ponto de vista - é um homem doente vindo vê-lo e pedindo um tipo especial de ajuda. Agora (...) - o que você vê?

ROGERS: Posso interromper aqui?

BUBER: Sim, por favor.

ROGERS: Sinto que se, do meu ponto de vista, esta for uma pessoa doente, então, eu não o ajudarei tanto quanto eu poderia. Sinto que essa é uma pessoa. Sim, outros podem chamá-lo de doente, ou se eu olhar para ele de um ponto de vista objetivo, então eu poderia concordar, também, "Sim, ele está doente." Mas ao entrar em uma relação, me parece que, se estou olhando para isso como "eu sou uma pessoa relativamente bem e esta é uma pessoa doente"...

BUBER: O que eu não quis dizer.

ROGERS:... e não servirá de nada.

BUBER: Eu não quis dizer... Permita-me deixar a palavra doente de fora disso. Uma pessoa vem até você para ser ajudada. A diferença, a diferença essencial - entre seu papel nessa situação e o dele - é óbvia. Ele vem para ser ajudado por você. Você não vem pedir ajuda a ele. E não só isso, mas você é capaz, mais ou menos, de ajudá-lo. Ele pode fazer diferentes coisas a você, mas não ajudálo. E não é só isso. Você o vê, realmente. Não quero dizer que você não possa se enganar, mas você o vê, exatamente como você disse, como ele é. Ele não pode, nem de longe, não pode ver você. Não somente em grau, mas no tipo de olhar. Você é, claro, uma pessoa muito importante para ele. Mas não uma pessoa que ele quer ver e conhecer e seja capaz disso. Você é importante para ele. Você é... ele 
está, desde o momento em que vem até você, ele está, eu poderia dizer, enredado na sua vida, nos seus pensamentos, no seu ser, na sua comunicação, e por aí afora. Mas ele não está interessado em você como você. Não pode ser. Você está interessado nele, você afirma isso e está correto, nele como essa pessoa. Este tipo de presença destacada ele não pode ter e dar. Esse é o primeiro ponto, até onde eu posso ver. E o segundo é - agora, por favor...

ROGERS: Uh, sim, eu não estou inteiramente seguro...

BUBER: Você pode me interromper a qualquer momento.

ROGERS: Ok, eu realmente quero entender isso. O fato de que sou capaz de vê-lo com menos distorção do que ele pode me ver e que eu tenho o papel de ajudá-lo e que ele não está tentando me conhecer neste mesmo sentido isso, é o que você quer dizer por "presença destacada"?

BUBER: Sim, h-mmm.

ROGERS: Eu apenas gostaria de ter certeza que eu...

BUBER: H-hmmm. Hmmm.

ROGERS: OK.

BUBER: Sim, sim, apenas isso.

ROGERS: Uh uhm.

BUBER: Agora, o segundo fato, até onde eu posso ver, está na situação que você tem em comum com ele, mas de dois lados. Você está de um lado da situação, no lado, eu poderia dizer, mais ou menos ativo, e ele no mais ou menos paciente, não inteiramente ativo, nem inteiramente passivo, é claro, mas relativamente. E essa situação - vamos agora olhar para essa situação comum, do seu ponto de vista e do ponto de vista dele. A mesma situação. Você pode vê-la, senti-la, experienciá-la, a partir dos dois lados. A partir do seu lado, vendo-o, observando-o, conhecendo-o, ajudando-o... e a partir do lado dele. Você pode experienciar, eu arriscaria dizer, corporalmente, o lado dele da situação. Quando você faz, por assim dizer, algo a ele, você se sente tocado pelo que fez a ele. Ele não consegue fazê-lo de maneira nenhuma. Você está do seu lado e do lado dele, ao mesmo tempo. Aqui e lá, ou, é melhor dizermos, lá e aqui. Onde ele está e onde você está. Ele não pode estar a não ser onde ele está. E isso, você tem a intenção de fazer, não só tem a intenção de fazer, você quer. Sua necessidade interna pode estar como ela é. Eu aceito isso. Não tenho objeção alguma. Mas a situação tem uma objeção. Você tem, necessariamente, outra atitude para com a situação que ele. Você é capaz de fazer algo que ele não é. Vocês não são iguais e não podem ser. Você tem a grande tarefa, autoimposta - a grande tarefa autoimposta de suplementar essa necessidade dele e fazer bem mais do que na situação normal. Mas, é claro, existem limites, e eu posso tomar a liberdade de dizer-lhe que certamente na sua experiência como terapeuta, como um curador ou ajudante da cura você deve tê-los experienciado com frequência - os limites da simples humanidade. "Simples humanidade" significando: Ser, eu e meu parceiro estarmos, por assim dizer, simila- res um ao outro, no mesmo plano. Eu vejo que você tem a intenção de estar no mesmo plano, mas você não pode. Não há só você, o seu modo de pensar, o seu modo de fazer, há também uma certa situação - somos isso ou aquilo - o que pode, às vezes, ser trágico, até mais terrível do que aquilo que chamamos trágico. Você não pode mudar isso. Humanidade, vontade humana, compreensão humana, não são tudo. Há também a realidade nos confrontando. Não podemos esquecer isso por nem um momento...

ROGERS: Bem o que você disse certamente provoca muitas reações em mim. Uma dela, penso, seja essa. Deixeme começar, primeiro, por um ponto que penso que concordaríamos... Suspeito que você concordaria que se esse cliente chega a um ponto onde ele pode experienciar o que ele está expressando, mas também pode experienciar minha compreensão e minha reação, e por aí afora, então, realmente a terapia já está praticamente finalizada.

BUBER: Sim. Isso é justamente o que eu quis dizer.

ROGERS: OK. Mas outra coisa que sinto é o seguinte. Às vezes, me questionei se isso é simplesmente uma idiossincrasia pessoal minha, mas me parece que quando uma outra pessoa está realmente se expressando e expressando sua experiência, etc., eu não sinto, da forma como você descreveu, diferente dele. Ou seja, não sei exatamente como colocar isso, mas sinto como se, naquele momento, a maneira dele olhar para a sua experiência, por mais distorcida que seja, é algo para o qual posso olhar como tendo a mesma autoridade, a mesma validade que a forma como vejo a vida e a experiencio. Parece-me que é esta, realmente, a base para a ajuda, em certo sentido.

BUBER: Sim.

ROGERS: E sinto que há um verdadeiro sentido de "entre nós".

BUBER: Sem dúvida. Mas não estou falando agora do seu sentimento, mas de uma situação real. Quero dizer, vocês dois, como você acabou de dizer, a experiência dele. Nem você nem ele olham para a sua experiência. O assunto é exclusivamente ele e a experiência dele. Ele não pode, no curso de, digamos, uma conversa com você, ele não pode mudar a posição dele e perguntar a você, "Oh, doutor, onde você foi ontem? Oh, você foi ao cinema? Qual foi o filme e como ele impressionou você?? Ele não pode fazê-lo. Então, eu vejo e sinto muito bem o seu sentimento, sua atitude, sua participação. Mas você não pode mudar uma situação dada. Existe algo objetivamente real que confronta você. Não somente ele, a pessoa, confronta você, mas também a situação. Você não pode mudá-la.

ROGERS: Bem agora, agora eu estou me perguntando, quem é Martin Buber, você ou eu, porque o que eu sinto...

BUBER: Heh, heh, heh [Risos da audiência].

ROGERS: Porque...

BUBER: Eu não, eu não sou, por assim dizer, "Martin Buber" como, como você diz, com aspas...

ROGERS: Nesse sentido, eu também não sou "Carl Rogers" (Risos). 
BUBER: Veja, não sou um homem citado que pensa isso, isso e aquilo.

ROGERS: Eu sei.

BUBER: Estamos apenas falando a respeito de algo que nos interessa, talvez, na mesma medida. Você está em um outro tipo, você está sempre, eh, eh, em contato com, em contato prático com... ${ }^{11}$

ROGERS: Eu sei. Eu compreendo isso. Brincadeiras a parte, o que eu queria dizer é o seguinte. Que eu acho que você está bastante certo, que existe uma situação objetiva ali, uma situação que pode ser medida, que é real, sobre a qual várias pessoas poderiam concordar se a examinassem de perto. Mas, tem sido a minha experiência que essa é a realidade quando ela é vista a partir de fora, e que ela não tem nada a ver com a relação que produz terapia. Esta é algo de imediato, igual, um encontro de duas pessoas em bases iguais - apesar de, no mundo do Eu-Isso, poder ser vista como uma relação desigual.

BUBER: Agora, Dr. Rogers, este é o primeiro ponto onde nós devemos dizer um ao outro, "nós discordamos".

ROGERS: Ok [Sorrisos].

BUBER: Veja, você não pode olhar só para você, para sua parte nas coisas, para a sua experiência [Rogers: Uh hum]. Vamos pegar o caso onde eu pudesse falar com ele, com o paciente, também. Iria, é claro, ouvir dele uma história muito diferente sobre esse mesmo momento [Rogers: Sim]. Agora, veja, não sou um terapeuta. Estou interessado em você e nele [Rogers: Uh hun]. Tenho que ver a situação. Tenho que ver você e ele nesse diálogo marcado pela tragédia. Às vezes, em muitos casos, a tragédia pode ser superada. Somente no seu método. Não tenho objeção alguma ao seu método, compreende? Não há necessidade de falar a respeito [Rogers: Uh hun]. Mas, às vezes, o método não é suficiente, e não pode ser feito o que - digamos - é necessário que seja feito. Agora, deixe-me fazer-lhe uma pergunta que aparentemente não tem nada a ver com isso [Rogers: Uh hun], mas é o mesmo ponto. Você certamente deve lidar bastante com esquizofrênicos. Verdade?

ROGERS: Um pouco. Uhm huh.

BUBER: E você também deve lidar, digamos, com paranóicos?

ROGERS: Um pouco.

BUBER: Agora, você diria que a situação é a mesma, em um caso e em outro? Quero dizer, a situação, na medida em que tem a ver com a relação entre você e o outro homem. Essa relação que você descreve é o mesmo tipo de relação em um caso e em outro? Você poderia falar, eh - esse é um caso, heh, uma questão que me interessa muito [Rogers: Uh hun], porque eu me interessei muito pela paranóia na minha juventude. Eu sei muito mais sobre esquizofrenia [Rogers: Uh hun], mas frequentemente me

\footnotetext{
${ }^{11}$ Neste momento há omissão de partes do diálogo na transcrição (Nota do Editor). Podemos acompanhar esse dado em Rob Anderson \& Kenneth Cissna (1997) (Eds.). The Martin Buber-Carl Rogers Dialogue. A New Transcript with Commentary. Albany: State University of New York Press.
}

interesso muito e gostaria de saber, você - isso significaria muito - você pode encontrar o paranóico exatamente da mesma forma?

ROGERS: Deixe-me primeiro qualificar minha resposta até certo ponto. Não trabalhei em um hospital psiquiátrico. Tenho lidado com pessoas que, em sua maioria, são capazes de algum tipo de ajustamento na comunidade, assim, eu não atendo pessoas realmente cronicamente doentes...

BUBER: Oh, percebo.

ROGERS: Por outro lado, nós lidamos com indivíduos que são esquizofrênicos e outros que são certamente paranóicos. Uma das coisas que falo muito, com muito cuidado, porque entendo que isso encontra oposição de peso na opinião psiquiátrica e psicológica, eu diria que não há diferença na relação que formo [Buber: $\mathrm{Hmm}] \mathrm{com}$ uma pessoa normal, um esquizofrênico e um paranóico [Buber: Hmm] eu realmente não sinto nenhuma diferença [Buber: Hmm]. Isso não significa, é claro, que quando... Bem, novamente essa é uma questão de olhar a partir de fora. Olhando a partir de fora, alguém pode facilmente discernir várias diferenças.

BUBER: Não, não, eu não quero dizer...

ROGERS: Eu também não... Mas me parece que se a terapia é efetiva, existe o mesmo tipo de encontro de pessoas, não importa qual seja o rótulo psiquiátrico. E, e, um pequeno ponto em relação a algo que você disse que me tocou. Parece-me que o momento onde as pessoas têm maior probabilidade de mudar, ou até penso neles como momentos em que as pessoas de fato mudam, são os momentos nos quais, talvez, os relacionamentos são experienciados da mesma forma dos dois lados. Quando você disse que se falasse com meu paciente [Buber: Uh] você teria um quadro muito diferente, eu concordo - isso seria verdade em relação à grande maioria das coisas que acontecem na entrevista. Mas, eu esperaria que naqueles momentos em que a mudança real ocorreu [Buber: Uh hun], que seria porque houve um encontro real de pessoas, no qual este foi experienciado da mesma forma dos dois lados.

BUBER: Uh huh, sim. Isso é realmente importante, eh...

FRIEDMAN: Posso inserir uma questão aqui?

BUBER: Não. Você poderia esperar um momento? [Friedman: Ok]. Só quero explicar ao Dr. Rogers porque essa questão é particularmente importante [Rogers: Uh hun] para mim e a sua resposta também. Um ponto muito importante no meu pensamento é o problema dos limites. Quero dizer, eu faço algo, tento alguma coisa, quero alguma coisa e dou todos os meus pensamentos na existência neste fazer. E então, num certo momento, chego a um muro [Rogers: Hum], a uma fronteira, a um limite que não posso, não posso ignorar. Eh, isso é verdade, também, pois o que me interessa mais do que tudo, é o diálogo humano efetivo. Diálogo pode ser silêncio. Você pode, nós poderíamos, talvez, sem uma platéia. Recomendaria fazê- 
lo sem uma platéia. Eh, eh, nós poderíamos nos sentar ou, de preferência, caminhar juntos [Rogers: Uh hun] em silêncio [Rogers: Uh hun] e isso poderia ser um diálogo. [Rogers: Uh hun] Mas assim, mesmo em diálogo, diálogo completo, há um limite determinado [Rogers: Uh hun]. É por isso que estou interessado na paranóia. Aqui está um limite determinado para o diálogo. Às vezes, é muito difícil falar com um esquizofrênico. Ele, em alguns momentos - na medida da minha experiência com isso, claro, como posso dizer, diletante? [Rogers: Uh hun] - posso falar com um esquizofrênico na medida em que ele está disposto a me deixar entrar no mundo particular [Rogers: Uh hun] que é só seu, e que, em geral, ele não quer que você ou outras pessoas entrem. Mas ele permite que algumas pessoas entrem. E assim, ele pode me deixar entrar também. Mas, no momento em que ele se fecha, não posso prosseguir. E, da mesma maneira, só que de uma maneira terrível, terrivelmente forte, é o caso de um paranóico. Ele não se abre e não se fecha. Ele é fechado. Há algo mais sendo feito a ele que o fecha. E é o terror deste destino que estou sentindo de forma tão forte, porque no mundo do homem normal, há casos análogos [Rogers: Uh hun], quando um homem são se comporta, não para com todos, mas para com algumas pessoas, exatamente desta forma, sendo fechado. E o problema é se ele pode ser aberto, se ele pode abrir-se, e por aí afora. E esse é um problema para o humano em geral.

ROGER: Sim, acho que vejo isso como...

BUBER: Agora, o Dr. Friedman quer trazer algo...

FRIEDMAN: Esse é meu papel como moderador. Não estou muito satisfeito sobre se, nessa troca logo antes do paranóico-esquizofrênico, até que ponto é uma questão, até que ponto pode ser um diferente uso dos termos, assim, deixe-me questionar o Dr. Rogers um pouco além. Da maneira como eu compreendi, o que Buber disse foi que essa é uma relação Eu-Tu, mas não totalmente recíproca, no sentido de que ao mesmo tempo em que você tem o encontro, você o vê a partir do ponto de vista dele, e ele não pode ver a partir do seu. E na sua resposta a isso, você apontou repetidas vezes para o encontro que acontece e até para a mudança que pode ocorrer em ambos os lados. Mas, eu não o ouvi sugerir que ele não vê a partir do seu ponto de vista, ou que seja completamente recíproco, no sentido que ele também o está ajudando. E eu me pergunto se essa não pode ser, talvez, exatamente a diferença, se não de palavra, de pontos de vista, onde você estava pensando em como você se sente em relação a ele, que ele é uma pessoa como você e que você o respeita.

BUBER: Permanece uma diferença decisiva. Não é uma questão de ter objeções em ajudar o outro. É uma questão de querer ajudar o outro. Ele é um homem querendo ajudar o outro [Rogers: Sim]. E ele, toda a sua atitude é essa atitude ativa, de ajuda. Isso é [Rogers: $\mathrm{Hhm}$ ], o que eu quero dizer é que há, por todos os céus, mas eu preferiria dizer por todos os infernos, a diferença da sua atitude [Rogers:
Uh hun]. Esse é um homem no inferno [Rogers: Uh hun]. Um homem no inferno não pode pensar, nem pode imaginar ajudar o outro. Como ele poderia?

ROGERS: Mas é, aqui, é aqui que algumas diferenças surgem. Porque me parece novamente que nos momentos mais reais da terapia não creio que essa intenção de ajudar seja algo mais que um substrato da minha parte, também. Em outras palavras, certamente não estaria fazendo esse trabalho se essa não fosse parte da minha intenção. E quando atendo o cliente pela primeira vez, o que desejo é ser capaz de fazer, é ser capaz de ajudá-lo. E, ainda assim, no intercâmbio do momento, eu não penso que minha mente seja tomada pelo pensamento do "agora eu quero ajudar você." É muito mais um "quero compreender você. Que pessoa é você, por trás dessa tela paranóica, ou por trás de toda essa confusão esquizofrênica, ou por trás de todas essas máscaras que você usa na sua vida real" [Buber: Huh, uh huh]. "Quem é você?”. E, eu não sinto que, que, me parece que é um desejo de encontrar a pessoa, não um "agora quero ajudar". Parece-me que isso é mais do que um: aprendi através da minha experiência que quando nós podemos nos encontrar, então a ajuda acontece, mas isso é um subproduto.

FRIEDMAN: Dr. Rogers, você não concordaria, pensaria, que isso não é completamente recíproco, no sentido que aquele homem não tem a mesma atitude para com você: "Eu quero entender você. Que tipo de pessoa é você?".

ROGERS: A única modificação que fiz disso foi que, talvez, no momento em que a mudança real acontece, então me pergunto se não é recíproco, no sentido que eu sou capaz de ver esse indivíduo como ele é naquele momento [Buber: Huh, huh] e ele realmente sente minha compreensão e minha aceitação. E, é isso que penso ser recíproco e, talvez, o que produz mudança.

BUBER: Hmmm, Eu, é claro, estou completamente de acordo com você na medida da sua experiência. Eu não posso estar de acordo com você, na medida em que tenho que olhar para toda a situação, a sua experiência e a dele. Veja, você dá a ele algo para fazê-lo igual a você. Você suplementa a necessidade dele na relação que ele estabelece com você. Você o coloca - numa certa - se posso dizer pessoalmente, a partir de uma certa plenitude, você lhe dá o que ele quer para ser capaz de estar, só por esse momento, por assim dizer, no mesmo plano que você. Mas, mesmo isso é muito - é uma tangente. É uma tangente que pode não durar mais do que um momento. Não é uma situação, na medida em que a vejo, não é uma situação de uma hora, é uma situação de minutos. E esses minutos são tornados possíveis por você. Não por ele, de forma alguma.

ROGERS: Eu concordaria plenamente com esse final - mas sinto uma divergência real aqui, porque me parece que o que eu dou a ele é a permissão para ser [Buber: Huh, uh huh]. O que não é - o que é, de alguma forma, um pouco diferente de dar algo a ele, ou algo semelhante. 
BUBER: Eu penso que nenhum ser humano pode dar mais do que isso. Tornar a vida possível para o outro, ainda que só por um momento. Estou com você.

ROGERS: Bem, se não olharmos para fora, vamos concordar (Risos.)

BUBER: Agora, vamos continuar.

ROGERS: Eu realmente gostaria de passar para outro tópico [Buber: Huh, uh huh], porque da maneira que entendo o que você escreveu, me parece que percebo outro tipo de encontro que tem muito significado para mim, em meu trabalho e, que até onde sei, você ainda não falou a respeito. Agora, posso estar enganado a respeito disso, não sei; e o que quero dizer é que me parece que um dos tipos mais importantes de encontro ou relacionamento [Buber: H-hmmm], é o relacionamento da pessoa com ela mesma [Buber: H-hmmm]. Na terapia, - novamente, que tenho que trazer porque é a base da minha experiência.

BUBER: Claro.

ROGERS: - Eh, existem alguns momentos muitos vívidos, nos quais o indivíduo está encontrando alguns aspectos de si mesmo, um sentimento que ele nunca reconheceu antes, alguma coisa como um significado nele próprio que ele nunca soube antes, $\mathrm{e}$ - pode ser qualquer tipo de coisa: pode ser seu sentimento intenso de solidão, ou a terrível mágoa que ele sentiu [Buber: Hmmm], ou algo bastante positivo [Buber: Hmmm] como sua coragem, e por aí afora. Mas, de qualquer forma, nesses momentos, me parece que há algo que compartilha da mesma qualidade do que compreendo como um real relacionamento de encontro. Ele está no seu sentimento, e o seu sentimento está nele. E isso é algo que o inunda. Ele nunca experienciou isso antes. Num sentido muito real, penso que isso poderia ser descrito como um encontro real com um aspecto dele próprio, que ele nunca havia encontrado antes. Agora, não sei se isso lhe parece um exagero, com respeito ao conceito que você usou. Acho que simplesmente gostaria [Buber: Hum] de saber a sua reação a isso. Se, para você parece um tipo possível de relacionamento real ou encontro? Vou levar isso um pouco mais adiante. Creio que tenho a sensação que, é quando a pessoa se encontrou consigo própria nesse sentido, provavelmente em inúmeros aspectos diferentes que, então e, talvez somente então, ela é realmente capaz de encontrar um outro numa relação Eu-Tu.

BUBER: Agora, aqui nos aproximamos do problema da linguagem [Rogers: Uh hum]. Você chama de diálogo algo que não posso chamar [Rogers: Uh hun]. Mas posso explicar por que não posso chamar assim. Porque eu iria querer um outro termo, entre diálogo e monólogo para esse caso. Agora, para o que chamo de diálogo, é essencialmente necessário o momento de surpresa. Quero dizer...

ROGERS: Você disse "surpresa”?

BUBER: Sim, ser surpreendido [Rogers: Uh hum]. Um diálogo - vamos tomar uma imagem bem trivial. O diálogo é como um jogo de xadrez. Todo o charme do xadrez é que não sei e não posso saber o que meu parceiro vai fazer.
Sou surpreendido pelo que ele faz e é nessa surpresa que todo o jogo está baseado. Agora, você sinaliza para isso, que um homem pode surpreender a si mesmo [Rogers: Uh hum]. Mas de uma maneira muito diferente de como uma pessoa pode surpreender outra pessoa. Eh -

[Enquanto essa fita estava sendo trocada, Dr. Buber continuou sua descrição das características de um diálogo verdadeiro. Um segundo aspecto é que no encontro verdadeiro, ou diálogo, aquilo que é diferente na outra pessoa, a sua alteridade é valorizada].

ROGERS: Os primeiros dois aspectos disso - Eu espero que talvez, em algum momento, possa lhe mostrar gravações das entrevistas para indicar como o elemento surpresa pode estar ali. Ou seja, a pessoa pode estar expressando algo e, de repente, ser tocada por um significado de algo que vem de um lugar nele mesmo, o qual ele não reconhece. Em outras palavras, ele realmente é surpreendido por si próprio. Isso, isso definitivamente pode acontecer. Porém, o elemento que eu vejo como sendo mais estranho ao seu conceito de diálogo é que essa alteridade, nela mesma, não é algo a ser valorizado [Buber: Humm]. Eu acho que - nesse tipo de diálogo a que me refiro, dentro da própria pessoa, é que há essa alteridade que seria, provavelmente, destruída. E eu compreendo que, em parte, toda a discussão a esse respeito pode estar baseada no uso diferente de palavras, também. O que quero -

BUBER: E, veja, posso acrescentar uma questão técnica? [Rogers: Uh hum]. Aprendi, no decorrer da minha vida, a valorizar as palavras [Rogers: Uh hum]. E penso que, na psicologia moderna, isso não acontece na medida suficiente. Quando encontro algo que é essencialmente diferente de outra coisa, quero uma nova palavra [Rogers: Uh hum]. Quero um novo conceito [Rogers: Uh hum]. Veja, por exemplo, a psicologia moderna, em geral, diz sobre o inconsciente que ele é uma certa forma de psique. Isso não tem sentido algum para mim. Se algo é tão diferente - se duas coisas são tão diferentes de uma outra, como essa tensão da alma, mudando a cada momento, onde eu não posso entender coisa alguma, quando tento entender - de um lado - eh, esse ser em tempo absoluto, e isso,uh, o que chamamos de inconsciente, isso não é um fenômeno de maneira alguma. Nós não podemos, não podemos ter acesso a isso, temos apenas que lidar com seus efeitos, e por aí afora. Não podemos dizer que o primeiro é psíquico e o segundo é psíquico; que o inconsciente é algo no qual psíquico e fisiológico estão, como posso dizer, misturados, não é suficiente. Eles se interpenetram de tal maneira que vemos, em relação a isso, que os termos corpo e alma são, por assim dizer, termos antigos [Rogers ri], conceitos tardios e consciência uma realidade primal. Agora, como podemos compreender esse conceito único?

ROGERS: Eu concordo muito com você a esse respeito, mas eu penso que quando uma experiência é, definitivamente, de um tipo diferente, então ela merece um ter- 
mo diferente. Penso que concordamos sobre isso. Talvez, como vejo que o tempo está passando, gostaria de levantar outra questão que tem muito sentido para mim e não sei bem como colocar. Deixe-me expressá-la mais ou menos assim: Quando vejo pessoas entrando em relacionamentos na terapia, penso que uma das coisas que passei a acreditar e sentir e experienciar é que aquilo que eu considero natureza humana ou natureza humana básica - esse termo é pobre e você deve ter uma forma melhor de expressar isso - é, realmente, algo em que se pode confiar. Parece-me que, em alguns dos seus escritos, eu percebo um pouco desse mesmo sentimento. De qualquer forma, minha experiência em terapia tem mostrado que não é necessário fornecer motivação em direção ao positivo, em direção ao construtivo. Isso existe no indivíduo. Em outras palavras, se pudermos libertar o que é mais básico no indivíduo, isso será construtivo. Agora, não sei... novamente, somente espero que, talvez, isso possa provocar alguns comentários da sua parte.

BUBER: Ainda não entendi a questão exata nisto.

ROGERS: A única questão que estou levantando é: "Você concorda"? Ou, se não estou sendo claro, por favor, faça-me outras perguntas. Tentarei colocar de outra forma. Bem, isto, pode ser um caminho contrastante [Buber: $H \mathrm{~mm}$ ]. Parece-me que, muito no caminho da psicanálise ortodoxa, ao menos, que tem sustentado que quando o indivíduo é revelado, quero dizer que quando você realmente chega ao fundo do que está dentro da pessoa [Buber: Hmmm], ela consiste, principalmente, de instintos, atitudes, e assim por diante [Buber: Hmmm], que devem ser controladas. E, isso vai em direção diametralmente oposta à minha própria experiência, que é que quando você chega ao que é mais profundo no indivíduo, esse é o exato aspecto que mais pode ser confiado, em termos de ser construtivo e tender em direção à socialização ou em direção ao desenvolvimento de melhores relações interpessoais. Isso faz sentido para você?

BUBER: Entendo. Eu gostaria de colocar isto de uma forma um pouco diferente. Até onde entendo, quando tenho a ver com, eu diria, uma pessoa problemática, ou simplesmente uma pessoa doente, uma pessoa que as pessoas chamam, ou querem chamar, uma pessoa má [Rogers: Uh huh]. Veja, em geral, o homem que tem realmente a ver com o que chamamos espírito, é chamado não pelas boas pessoas, mas somente pelas pessoas más, pelos problemáticos, pelos inaceitáveis, e por aí afora. As boas pessoas podem ser amigas dele, mas não necessitam dele. Então, estou interessado somente nos tão chamados maus, problemáticos e por aí afora. E a minha experiência é se eu tiver êxito em, e isso está próximo do que você diz, mas é um tanto diferente, se me aproximar da realidade dessa pessoa, a experiencio como uma realidade polar.

ROGERS: E o que é isso? Polar?

BUBER: Realidade polar [Rogers: Uh huh]. Veja, em geral, dizemos que isso é ou A ou Não-A. Não pode ser A e Não-A ao mesmo tempo [Rogers: Uh huh]. Não pode. Não pode. Quero dizer, aquilo que você afirma ser confiável. Eu diria que se situa em relação polar com o que menos pode ser confiável nesse homem. Você não pode dizer, e talvez eu me diferencie de você nesse ponto, você não pode dizer, "Oh, detecto nele exatamente o que é confiável”. Eu diria, agora, quando o vejo, quando o compreendo mais amplamente e mais profundamente que antes, vejo toda a sua polaridade e, então, vejo como o pior e o melhor nele são dependentes um do outro, ligados um ao outro. E posso ajudar - é possível que eu seja capaz de ajudá-lo - simplesmente ajudando-o a modificar a relação entre os polos. Não simplesmente pela escolha, mas através de uma certa força que ele dá a um dos polos em relação ao outro, os polos sendo qualitativamente muito similares um ao outro. Eu diria que não há, como pensamos geralmente, na alma de um homem o bem e o mal opostos. Existe, muitas vezes e de diferentes maneiras, uma polaridade; e os polos não são bem e mal mas, mais exatamente, sim e não, mais exatamente, aceitação e recusa [Rogers: Uh huh]. E, podemos fortalecer, ou ajudá-lo a fortalecer, o polo positivo. E, talvez, possamos até fortalecer o controle de direção nele, porque essa polaridade é, frequentemente, sem direção. É um estado caótico. Poderíamos trazer uma nota cósmica. Podemos ajudar a por ordem, a por forma. Porque penso que o bem, o que podemos chamar de bem, é sempre só direção. Não uma substância.

ROGERS: Se eu tomar essa última parte particularmente, você está dizendo que talvez possamos ajudar o indivíduo a fortalecer o sim, que é afirmar a vida ao invés de recusá-la. É isso...?

BUBER: M-hummmm. Veja, eu discordo somente nessa palavra, eu não diria vida, eu não colocaria um objeto.

ROGERS: Um huh.

BUBER: Eu gostaria de dizer simplesmente "sim".

ROGERS (para Dr. Friedman): Você parece estar querendo dizer alguma coisa. Acho que poderíamos continuar sobre isso para sempre.

FRIEDMAN: Minha função como moderador é estimular as questões e sinto que duas questões interrelacionadas foram mencionadas aqui, mas, talvez, não evidenciadas, e sinto que é muito importante, eu gostaria de entender. Quando Dr. Rogers perguntou ao Professor Buber sobre sua atitude em relação à psicoterapia, ele mencionou como um dos fatores componentes da sua abordagem à terapia, a "aceitação". Agora, Professor Buber, como vimos ontem à noite, frequentemente usou o termo confirmação, e tenho a sensação, tanto a partir do que eles disseram hoje quanto do meu conhecimento dos seus escritos, que pode ser realmente importante clarificar se eles querem dizer aproximadamente o mesmo. Dr. Rogers escreve sobre aceitação, além de dizer que é um olhar caloroso pelo outro e um respeito pela sua individualidade, por ele como uma pessoa de valor incondicional, diz que significa "uma aceitação e consideração por suas atitudes 
do momento, não importando quão negativa ou positiva, não importando o quanto elas podem contradizer outras atitudes que ele sustentou no passado". E “essa aceitação de cada aspecto flutuante desta outra pessoa estabelece para ele um relacionamento de calor e segurança". Agora, me pergunto se o Professor Buber consideraria confirmação similar a isso ou se ele veria confirmação como incluindo, talvez, não ser aceito, incluído alguma exigência sobre o outro, que poderia significar, num certo sentido, uma não-aceitação dos seus sentimentos no momento, a fim de confirmá-lo mais tarde.

BUBER: Eu diria que todo verdadeiro relacionamento existencial entre duas pessoas começa com aceitação. Por aceitação, quero dizer - talvez os dois conceitos não sejam exatamente iguais - por aceitação quero dizer ser capaz de dizer, ou melhor, não de contar, mas simplesmente fazer com que a outra pessoa sinta que eu o aceito exatamente como ele é. Eu tomo você exatamente como você é. Bem, então, mas não é ainda o que quero dizer com "confirmar o outro". Porque aceitar é simplesmente aceitar o outro, como quer que ele seja, nesse momento, nessa sua realidade. Confirmar significa, antes de tudo, aceitar toda a potencialidade do outro [Rogers: Uhm hum], e fazer até mesmo uma diferença decisiva em sua potencialidade e, é claro, podemos estar enganados repetidas vezes sobre isso, mas é só uma possibilidade entre os seres humanos. Posso reconhecer nele, conhecer nele, mais ou menos, a pessoa que ele foi - posso dizer somente com essa palavra - criado para se tornar. Em linguagem simples e factual, não encontramos o termo para isso porque não encontramos isso no termo, o conceito de "ser implica em tornar-se”. É isso que devemos, até onde possível, compreender, senão no primeiro momento, então depois disso. E agora eu posso, não somente aceitar o outro como ele é, mas confirmá-lo, em mim mesmo e, então nele, em relação a essa potencialidade que é significada por ele e que pode agora ser desenvolvida, pode evoluir, pode responder à realidade da vida. Ele pode fazer mais ou menos nessa esfera de ação, mas eu posso, também, fazer algo. E, isso é com objetivos ainda mais profundos que a aceitação. Tomemos, por exemplo, um homem e uma mulher, marido e mulher. Ele diz, não expressamente, mas simplesmente por toda a sua relação com ela, que "eu te aceito como você é." Mas isso não quer dizer "Eu não quero que você mude.” Mas diz, "Eu descubro em você, simplesmente através do meu amor acolhedor, descubro em você o que você está destinado a se tornar”. É claro, isso não é algo a ser expresso em termos massivos. Mas, pode ser que cresça e cresça com os anos de vida em comum. É isso que você quis dizer?

ROGERS: Sim. E penso que isso soa muito parecido com essa qualidade que está na experiência que eu penso como sendo aceitação, apesar de eu ter tendido a expressá-la de forma diferente. Eu penso que aceitamos o indivíduo e a sua potencialidade. Penso ser uma questão real se poderíamos aceitar o indivíduo como ele é, porque fre- quentemente ele está num estado lastimável, se não fosse pelo fato de que nós, em certo sentido, também compreendêssemos e reconhecêssemos seu potencial. Acho que sinto, também, que a aceitação de um tipo mais completo, aceitação dessa pessoa como ela é, é o mais forte fator de mudança que eu conheço. Em outras palavras, penso que isso libera a mudança, ou libera potencialidade de descobrir que como eu sou, exatamente como eu sou, eu sou completamente aceito - então não posso deixar de mudar. Porque, então, sinto que não existe mais a necessidade de barreiras defensivas e, então, o que assume o comando são os processos evolutivos da própria vida.

BUBER: Temo não estar tão certo disso quanto você está, talvez por não ser terapeuta. E, eu tenho necessariamente que lidar com esse tipo problemático. Eu não posso, na minha relação com ele, dispensar essa polaridade. Não posso por isso de lado. Como eu disse, tenho que lidar com ambos os homens. Tenho que lidar com o problemático nele. E tenho que... existem casos quando devo ajudá-lo apesar dele mesmo. Ele quer minha ajuda contra si mesmo. Ele quer... veja, o mais importante é que ele confia em mim. Sim, a vida tornou-se sem fundamento para ele. Ele não pode pisar em solo firme, em terra firme. Ele está, por assim dizer, suspenso no ar. E o que ele quer? O que ele quer é um ser, não somente em quem ele possa confiar, como um homem confia em outro, mas um ser que dá a ele a certeza de que "existe um solo, que existe uma existência. $\mathrm{O}$ mundo não está condenado à privação, degeneração, destruição. O mundo pode ser redimido. Eu posso ser redimido porque existe esta confiança”. E, se isso é alcançado, agora posso ajudar esse homem, mesmo na luta contra ele mesmo. E, isso eu só posso fazer se eu distinguir "aceitar" de "confirmar".

ROGERS: Sinto que uma dificuldade com um diálogo é que pode facilmente não ter fim, mas penso que por piedade tanto do Dr. Buber quanto da platéia, esse... [Risos].

BUBER: O que você disse?

ROGERS: Disse que por consideração a você...

BUBER: Não por mim, heh heh.

ROGERS: Tudo bem... [risos]... por consideração à platéia.

FRIEDMAN: Permitam-me ser impiedoso e colocar uma última questão. É assim [Buber: Huh huh]. Minha impressão é que, por um lado, houve mais insistência por parte do Dr. Rogers na completa reciprocidade da relação Eu-Tu na terapia, e menos por parte do Dr. Buber; mas por outro, tenho a impressão que o Dr. Rogers é mais centrado no cliente...

BUBER: O quê?

FRIEDMAN: Mais centrado no cliente... (risos) mais preocupado, mais preocupado com o tornar-se da pessoa. E Dr. Rogers fala, em um artigo recente ${ }^{12}$, de ser capaz de

\footnotetext{
${ }^{12}$ Neste momento Friedman se refere a um texto de Rogers intitulado "What It Means to Become a Person", posteriormente publicado como o capítulo VI do livro On Becoming a Person (em sua edição americana). Na edição brasileira, este capítulo foi suprimido.
} 
confiar no organismo de alguém, que ele encontrará satisfação, que ele expressará a si. E fala do locus do valor como estando dentro de alguém, enquanto que tenho a impressão, a partir do meu encontro com Dr. Buber, que ele vê valor mais no "entre". Gostaria de saber se esse realmente é um ponto de controvérsia entre vocês dois.

ROGERS: [Buber: Hum] Posso expressar minha visão sobre isso, hum, em termos um pouco diferentes daqueles que você usou e, ainda, eu penso que está relacionado à mesma coisa. Como tentei pensar nos últimos meses, me parece que você poderia falar do objetivo em direção ao qual a terapia se move, e acho que o objetivo em direção ao qual a maturidade se move em um indivíduo, como sendo um "tornar-se", ou sendo consciente e aceitando aquilo que se é mais profundamente. Em outras palavras, isso também expressa uma confiança real no processo no qual nos encontramos, o qual não pode ser inteiramente compartilhado entre nós hoje.

BUBER: Talvez ajudasse se eu apontasse um problema que encontrei quando li exatamente esse seu artigo [Rogers: Huh huh], ou um problema que me veio [Rogers: Huh huh]. Você fala sobre pessoas, e o conceito de "pessoa” é aparentemente muito próximo do conceito de "indivíduo”. Penso ser aconselhável estabelecer uma distinção entre eles. Um indivíduo é somente uma certa singularidade de um ser humano. E ele pode se desenvolver somente através do desenvolvimento de sua singularidade. É isso que Jung chama de "individuação". Ele pode tornar-se mais e mais um indivíduo sem tornar-se mais e mais humano. Eu tenho [Rogers: Huh huh] muitos exemplos de homens que se tornaram muito, muito individuais, muito distintos dos outros, muito desenvolvidos em suas particularidades sem ser, de maneira alguma, o que eu gostaria de chamar um homem [Rogers: Huh huh]. Indivíduo é somente esta singularidade, capaz de ser desenvolvido e por aí afora. Mas pessoa, eu diria, é um indivíduo vivendo realmente com o mundo. E com o mundo, não quero dizer no mundo [Rogers: Huh huh], mas exatamente em contato real, em real reciprocidade com o mundo em todos os pontos nos quais o mundo pode encontrar o homem. Não digo somente com o homem, porque às vezes podemos encontrar o mundo de formas outras que a do homem. Mas isso é o que eu chamaria uma pessoa e se eu posso dizer expressamente "sim" e "não" a certos fenômenos, sou contra indivíduos e a favor de pessoas [Aplausos].

ROGERS: Uhm, huh. Correto. [Aplausos]

FRIEDMAN: Nós temos razão em dizer que devemos muito ao Dr. Rogers e ao Dr.Buber por esse, esse diálogo único. É certamente único na minha experiência: primeiro, por ser um verdadeiro diálogo, diante de uma audiência e, eu penso que, isto se deve em parte pelo que eles desejavam nos dar e nos deram e, em parte, por que vocês [a audiência] tomaram parte, algo como, um triálogo, ou me acrescentando, um, um quadriálogo, no qual vocês participaram silenciosamente [Aplausos].

\section{Nota Biográfica}

Mordechai Martin Buber (1878-1965) nasceu em Viena e foi educado na "polaridade existente entre o ocidente e o oriente". Teólogo, filósofo e escritor; desenvolveu sua "filosofia dialógica" descrita em uma obra que alia filosofia e teologia. Grande divulgador do Hassidismo e do Judaísmo, Buber publica em 1913, Daniel (ainda inédito no Brasil), mas ficou mais conhecido por seu livro Ich und Du (Eu e Tu, São Paulo: Centauro). Possui ainda numerosa obra em temas que tocam e influenciam a sociologia, psicologia e antropologia, vários deles traduzidos para o português: $D o$ Diálogo e do Dialógico (São Paulo: Perspectiva); Eclipse de Deus (Campinas: Verus); Sobre Comunidade (São Paulo: Perspectiva); O Socialismo Utópico (São Paulo: Perspectiva); As Histórias do Rabi Nachmann (São Paulo: Perspectiva); A Lenda do Baal Schem (São Paulo: Perspectiva) e Histórias do Rabi (São Paulo: Perspectiva). Buber é considerado alicerce e suporte filosófico para numerosas práticas clínicas e referência obrigatória quando o tema é "diálogo".

Carl Ramson Rogers (1902-1987) era psicólogo, humanista e cientista brilhante. Criador da "terapia centrada no cliente", fez com que seu pensamento transcendesse as fronteiras da clínica psicoterapêutica, constituindo-se nos mais diversos campos de aplicação. Com isto, criou os "Grupos de Encontro", o "Ensino Centrado no Estudante", até sua abordagem ser conhecida por Abordagem Centrada na Pessoa. Seu interesse por Teologia se deve ao fato de haver seguido cursos no Union Theological Seminary, onde Tillich lecionou, entre 1924 e 1926, de onde migra para o Teacher's College da Columbia University. Grande parte de sua obra está traduzida para o português, com destaque para seu livro mais conhecido Tornar-se Pessoa (São Paulo: Martins Fontes). Temos ainda as seguintes traduções: Grupos de Encontro; Psicoterapia e Consulta Psicológica; Sobre o Poder Pessoal; O Tratamento Clínico da Criança-Problema e Carl Rogers. O Homem e suas Idéias (pela editora Martins Fontes, São Paulo); Um Jeito de Ser e A Pessoa como Centro (pela E.P.U.); além de Em Busca de Vida (Summus); Quando Fala o Coração (Vetor); Novas Formas de Amor (José Olympio); Abordagem Centrada na Pessoa (Editora da UFES); O Homem e a Ciência do Homem; Psicoterapia e Relações Humanas e Liberdade para Aprender (Interlivros) e Liberdade para Aprender em Nossa Década (Artes Médicas).

Tradução: Andréa de Alvarenga Lima Revisão Técnica: Adriano Holanda 